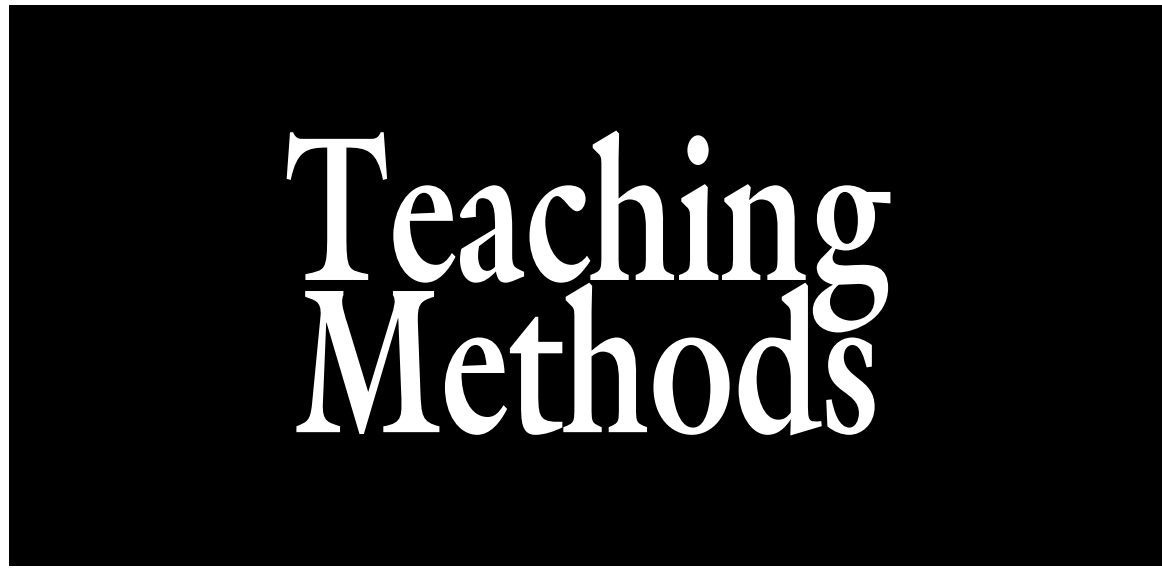

\section{An Online Study Tool for Reviewing Plant Propagation Terms and Concepts}

\author{
Sandra B. Wilson ${ }^{1,4,6}$, Robert L. Geneve ${ }^{2,4}$, and Fred T. Davies ${ }^{3,5}$
}

AdDitional INDEX wORDs. distance education, active learning, web technology, seed propagation, vegetative propagation, micropropagation

SUMMARY. Interactive web-based questions were developed for students to review subject matter learned in an online plant propagation course. Articulate Storyline software was used to build nearly 250 review questions with five different testing styles to ascertain proficiency in subject areas, including the biology of propagation, the propagation environment, seed propagation, vegetative propagation, micropropagation, and cell culture. Questions were arranged to correspond to the supporting textbook chapters in Hartmann and Kester's Plant propagation: Principles and practices, ninth edition. These are open access and available to instructors and students worldwide. Users received immediate feedback for each question answered correctly or incorrectly. The system remembers where one leaves off, which enables starting and stopping multiple times within a chapter. Means of preand posttest responses to nine content knowledge items showed that students perceived a significant content knowledge gain in the course. These online interactive reviews can be adapted easily to other courses in a variety of fields, including horticulture, botany, systematics, and biology. They can also be expanded to overlay multiple objects and trigger events based on user response. Since inception, the website hosting these online reviews averaged 156 unique visitors per month. Students have reported this to be a useful tool to prepare them for course exams.

$\mathrm{D}$ istance education enrollments have increased for the 14th straight year. Currently, $31.6 \%$

We gratefully acknowledge financial support from the College of Agricultural and Life Sciences University of Florida (CALS-UF) mini-grant program for instructional improvement for distance education.

We extend gratitude to Aaron Sotala, Keona Nolan, and Carlee Steppe for their assistance.

${ }^{1}$ Department of Environmental Horticulture, Institute of Food and Agricultural Sciences, University of Florida, P.O. Box 110675, Gainesville, FL 32611-0675

${ }^{2}$ Department of Horticulture, 401B Plant Science Building, University of Kentucky, Lexington, KY 40546-0312

${ }^{3}$ Department of Horticultural Sciences, 2133 Texas A\&M University, College Station, TX 77843-2134

${ }^{4}$ Professor.

${ }^{5}$ Professor Emeritus.

${ }^{6}$ Corresponding author. E-mail: sbwilson@ufl.edu.

https://doi.org/10.21273/HORTTECH04184-18 and Dougher, 2011; Rieger et al., 2011). When asked to compare the efficacy of online vs. in-person courses on a range of objectives, an overwhelming majority of professors $(86 \%)$ said they believed online courses were less effective for interacting with students (Jaschik and Lederman, 2017).

With the rapid advances in distance education technologies, new approaches are continually sought to facilitate learning in an online environment. Online innovations not only serve to reinforce important subject knowledge but help meet a critical need when shifting from traditional, entirely synchronous instruction (handson live learning) to a hybrid or fully online approach with asynchronous components. Increasingly, technology offers opportunities to create powerful learning tools, regardless of the learning platform (Pitler et al., 2012). More and more, instructors who are teaching in person are also using courseware learning management platforms such as Blackboard Learn (Blackboard, Washington, DC) and Canvas (Instructure, Salt Lake City, UT) to deliver content resulting in a flipped classroom approach (Heyborne and Perrett, 2016).

A majority of students (72\%) feel their grades would improve if faculty used more technology in the classroom (Seaman et al., 2018). Likewise, instructors report the adequacy and availability of multimedia tools were limiting (Wright et al., 2010). Effective online formats use a variety of instructional strategies to enhance interactive learning, ensure critical thinking, and provide immediate feedback (Campbell et al., 2011; SchroederMoreno, 2010; Tignor et al., 2007; Wilson and Flory, 2012; Wilson and Thetford, 2003).

Described as "the purposeful act of reproducing plants," plant propagation has been practiced for at least 12,500 years and is considered a fundamental occupation of humankind (Davies et al., 2018). To meet the $70 \%$ increased demand in food production that will occur by the year 2050 , it is crucial that we develop students who can think critically and have access to the latest propagation and production technologies that they can then adapt to local situations. Video making, dynamic electronic presentations, interactive learning, and other teaching methods in plant propagation available universally in 


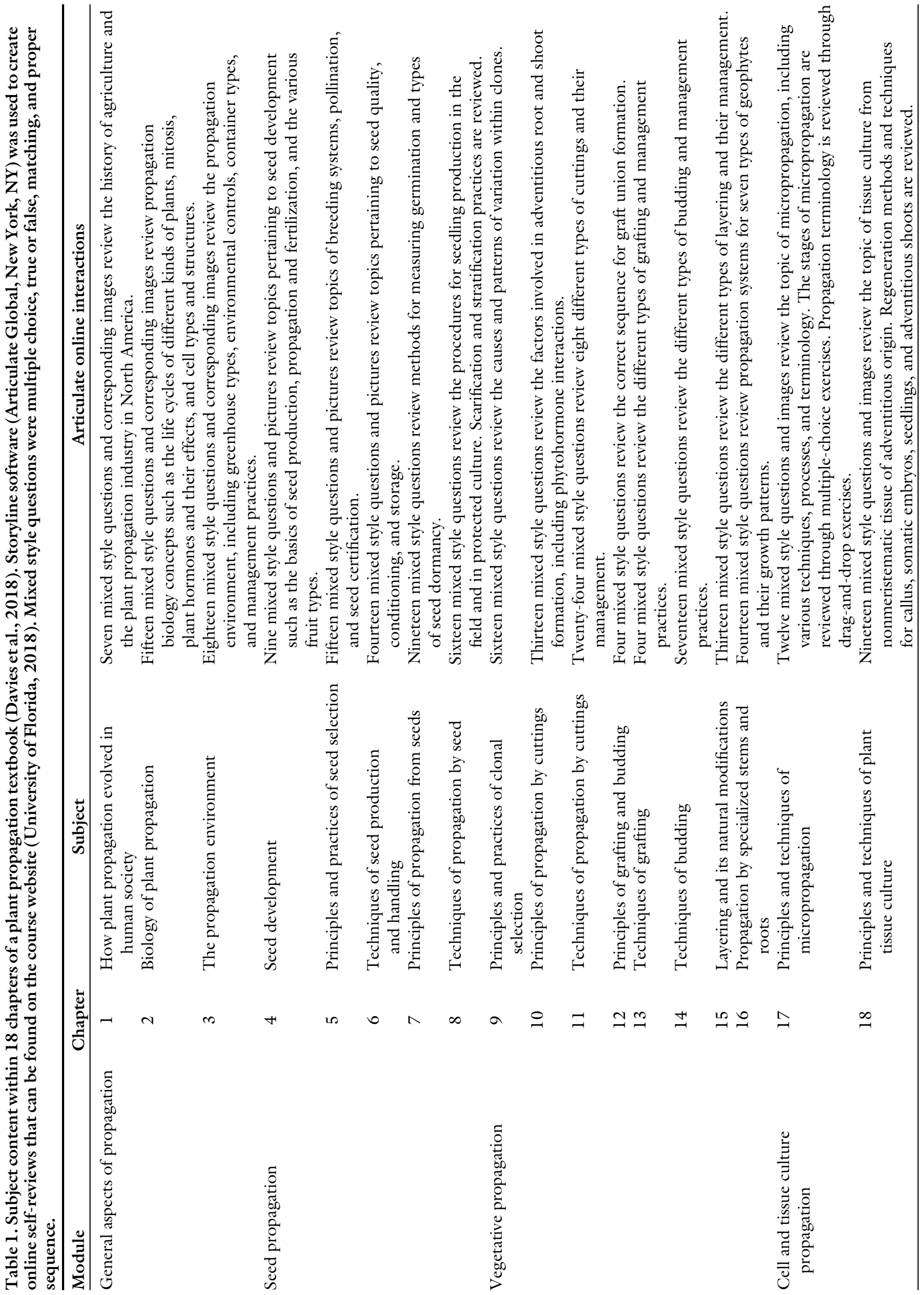


both the developing and developed world are critical in overcoming learning barriers.

The purpose of this project was to 1$)$ develop interactive, online quizzes for students to self- evaluate their understanding of concepts and terms introduced in an online plant propagation course, 2) make this available universally as a resource for all instructors and students, and 3) evaluate students' perceived content knowledge gain from using this teaching tool.

Quiz questions were generated from subject content found in the universal textbook used by most institutions, Hartmann and Kester's plant propagation: Principles and practices (Davies et al., 2018). This textbook is now in its ninth edition, with more 100,000 copies in print in several languages. The ninth edition consists of 18 chapters as described in Table 1 (Davies et al., 2018).

Storyline 3 software (Articulate Global, New York, NY) was chosen to build interactive review questions for each of the 18 chapters (Table 1 ) (Davies et al., 2018). Four different response styles were used, including multiple choice, true/false, proper sequence, and matching. Attractive features of the software are that it is readily available, easy to use, allows for multidevice interactive e-learning, and provides an intuitive user-friendly interphase. Video and audio can be incorporated easily into later versions.

A new open-access website page was created to host these Storyline interactions (University of Florida, 2018). Corresponding images from the chapters were included to enhance the overall visual appeal when appropriate. Users can drag and drop the correct term that matches a description and receive immediate feedback for each question answered correctly or incorrectly (Fig. 1). After all questions are answered, a final grade percentage appears on the screen. By selecting from a database of nearly 250 questions specific to the art and science of plant propagation, users can practice their propagation knowledge virtually anywhere and at any time.

All Storyline interactive online quizzes were made available at the course website (University of Florida, 2018) and assigned weekly through the course management system, along with the corresponding reading assignments. A pre- and posttest assessment

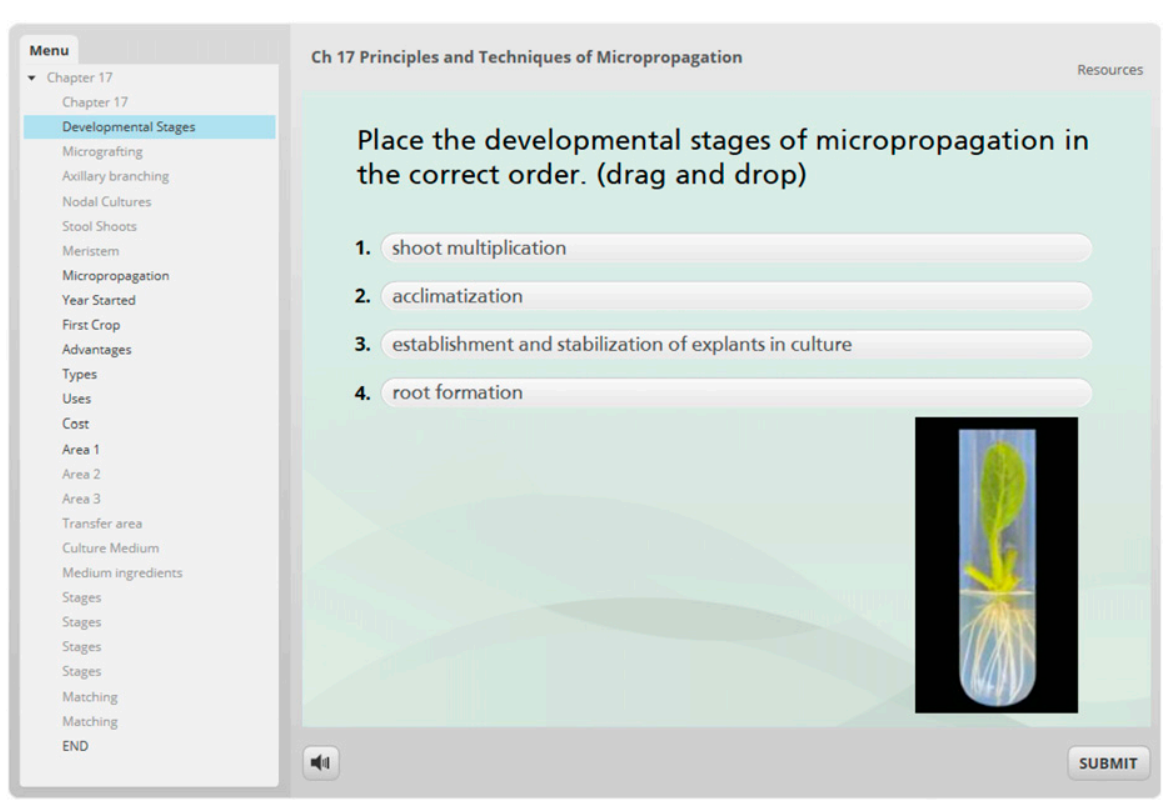

Fig. 1. Screenshot of an example self-review quiz question built using Storyline 3 software (Articulate Global, New York, NY). The student is asked to drag and drop the stages of micropropagation in proper order (University of Florida, 2018). After the SUBMIT button is clicked, the question is graded for immediate feedback. The menu to the left outlines all the questions associated with this chapter for a quick reference.

Table 2. Students' perceived pre- and posttest content knowledge means, difference, and significance $(n=19)$ in a plant propagation course that used interactive online self-review quizzes. Knowledge items used a Likert scale, with responses ranging from $\mathbf{l}$ (strongly disagree) to 5 (strongly agree); means were compared using a matched $t$ test.

\begin{tabular}{lccccc}
\hline Knowledge item & Premean & Postmean & Difference & $t$ test & Significance \\
\hline Genes & 3.28 & 4.11 & 0.83 & 0.27 & 0.012 \\
Sexual vs. asexual propagation & 4.06 & 4.50 & 0.44 & 0.03 & 0.190 \\
Plant life cycles & 3.56 & 4.33 & 0.78 & 0.04 & 0.009 \\
Seed development and & 3.44 & 4.33 & 0.89 & 0.23 & 0.001 \\
$\quad$ germination & & & & & \\
Plant hormones & 3.17 & 4.44 & 1.28 & 0.09 & 0.002 \\
Adventitious roots & 2.78 & 4.24 & 1.46 & 0.18 & $<0.0001$ \\
Grafting and budding & 2.72 & 4.50 & 1.78 & 0.42 & $<0.0001$ \\
Plant clone variation & 2.28 & 3.78 & 1.50 & 0.15 & $<0.0001$ \\
Micropropagation & 2.65 & 4.50 & 1.85 & 0.45 & $<0.0001$ \\
\hline
\end{tabular}

instrument was developed that included nine knowledge items designed to assess perceived knowledge change/ gain in plant propagation concepts. The resulting questionnaire was administered via the web course management system $(\mathrm{n}=19)$. Items used a Likert-type scale, with responses ranging from 1 (strongly disagree) to 5 (strongly agree). Means were calculated for both pre- and posttest responses to nine content knowledge items and then compared using a matched pairs $t$ test at $P=0.05$ using JMP Pro (version 14.1.0; SAS Institute, Cary, NC).
Results showed that on every level, except in their ability to differentiate between sexual and asexual propagation, students perceived a significant content knowledge gain from this course (Table 2). The greatest gain in perceived content knowledge was in micropropagation followed by grafting and budding. Verbal feedback from students who have used this tool has been positive. During the end-of-semester discussion session between the instructor and students, one student commented, "The online interactions were a fun way for me to test my knowledge of plant propagation 
before and after the course, and help me review for the final exam."

For instructors, additional test bank resources are available from the publisher (Pearson Education, New York, NY). Authors have created 422 test questions with answers that may be useful for creating exams. PowerPoint slides for each of the 679 figures in the textbook are also available. To register for an instructor access code, visit the Pearson website (Pearson Education, Inc., 2018).

\section{Literature cited}

Bigatel, P. and S. Edel-Malizia. 2018. Predictors of instructor practices and course activities that engage online students. Online J. Distance Learning Admin 21(1):4 Oct. 2018. <https://www.westga.edu/ distance/ ojdla/spring211/bigatel_malizia211.html $>$.

Campbell, K.R., S.B. Wilson, P.C. Wilson, and Z. He. 2011. Interactive online tools for teaching plant identification. HortTechnology 21:504-508.

Davies, F.T., Jr., R.L. Geneve, and S.B. Wilson. 2018. Hartmann and Kester's plant propagation: Principles and practices. 9th ed. Pearson Education, New York, NY.

Driscol, A., K. Jicha, A.N. Hunt, L. Tichavsky, and G. Thompson. 2012. Can online courses deliver in-class results? A comparison of student performance and satisfaction in an online versus a face-to-face introductory sociology course. Teach. Sociol. 40(4):312-331.
Heyborne, W.H. and J.J. Perrett. 2016. To flip or not to flip? Analysis of a flipped classroom pedagogy in a general biology course. J. Coll. Sci. Teach. 45:31-37.

Hoch, W.A. and T.A.O. Dougher. 2011. Student perceptions of hybrid vs. traditional courses: A case study in plant identification. North Amer. Colleges Teachers Agr. J. 55(4):8-13.

Jaschik, S. and D. Lederman. 2017. Survey of faculty attitudes on technology. A study by Inside Higher Ed and Gallup. 4 June 2018. <https://www.insidehighered. com/booklet/2017-survey-faculty-attitudestechnology $>$.

Means, B., Y. Toyama, R. Murphy, M. Bakia, and K. Jones. 2010. Evaluation of evidence-based practices in online learning: A meta-analysis and review of online learning studies. U.S. Dept. Educ., Washington, DC.

Pearson Education, Inc. 2018. Download instructor resources. 4 Oct. 2018. <https://www.pearson.com/us/highereducation/subject-catalog/downloadinstructor-resources.html>.

Pitler, H., E.R. Hubbel, and M. Kuhn. 2012. Using technology with classroom instruction that works. Mid-Continent Res. Educ. Learning, Denver, CO.

Rieger, M., R.E. Turner, and R.K. Barrick. 2011. Student evaluation scores for courses delivered by interactive videoconferencing. North Amer. Colleges Teachers Agr. J. 55(1):16-20.
Schroeder-Moreno, M.S. 2010. Enhancing active and interactive learning online: Lessons learned from an online introductory agroecology course. North Amer. Colleges Teachers Agr. J. 54(1):21-30.

Seaman, J.E., I.E. Allen, and J. Seaman. 2018. Grade increase: Tracking distance education in the United States. 19 Nov. 2018. <http://www.onlinelearningsurvey. com/highered.html $>$.

Tignor, M.E., S.B. Wilson, G.A. Giacomelli, C. Kubota, E. Fitz, T.A. Irani, E. Rhoades, and M.J. McMahon. 2007. Multiinstitutional cooperation to develop digital media for interactive greenhouse education. HortTechnology 17:397-399.

University of Florida. 2018. Creative tools: Plant propagation self-review quizzes. 8 June 2018. <http://irrecenvhort. ifas.ufl.edu/creative_tools.html $>$.

Wilson, S.B. and L. Flory. 2012. FloraGator: A novel, interactive, and online multiple-entry key for identifying plant families. Hort Technology 22:410-412.

Wilson, S.B. and M. Thetford. 2003. A new strategy for teaching plant propagation by distance education. HortTechnology 13:577-578.

Wright, A.N., J.A. Robbins, and M. Gu. 2010. Course content and attitudes toward instructional multimedia use in nursery management and production courses in the United States. HortTechnology 20:646-651. 